\title{
Health Professionals' Attitudes towards Digital Transformation through the Use of Hospital Information Systems: The Case of a General Oncology Hospital of Attica
}

\author{
Chrysostomos Natsis' ${ }^{1}$, Sofoklis Chrysanthopoulos ${ }^{2}$, Maria-Aggeliki Stamouli1 \\ ${ }^{1}$ Postgraduate Program in "Health and Social Care Management", Sector of Social Policy, Department of Business Administration, \\ University of West Attica, Athens, Greece \\ ${ }^{2}$ Hellenic Statistical Authority, Piraeus, Greece \\ Email:mastamouli@uniwa.gr
}

How to cite this paper: Natsis, C., Chrysanthopoulos, S., \& Stamouli, M.-A. (2020). Health Professionals' Attitudes towards Digital Transformation through the Use of Hospital Information Systems: The Case of a General Oncology Hospital of Attica. Open Journal of Social Sciences, 8, 321-335. https://doi.org/10.4236/jss.2020.810021

Received: September 24, 2020

Accepted: October 26, 2020

Published: October 29, 2020

Copyright (c) 2020 by author(s) and Scientific Research Publishing Inc. This work is licensed under the Creative Commons Attribution International License (CC BY 4.0).

http://creativecommons.org/licenses/by/4.0/

\begin{abstract}
Purpose: The study of the attitude of Health Professionals of the General Oncology Hospital of Attica towards the integrated Hospital Information Systems (HISs) as well as of the socio-demographic factors that shape it. Material-Method: A stratified sampling quantitative survey was conducted using the occupational category of the employees as the stratification variable. Data were collected by employing the standard Nurses Attitudes towards Computerization (NATC) self-report questionnaire. Statistical analysis was conducted with the use of the statistical data processing SPSS-v25 software. Results: The staff of the General Oncology Hospital under study have a positive attitude towards the use of Hospital Information Systems (Mean = 3.73, SD. = 0.54). Statistically significant differences between occupational categories were found only for the dimension of "Providing quality care to the patient" ( $p=$ 0.007 ) and more specifically among nurses and doctors. Regarding the effect of demographic factors on the five dimensions that form the attitude of health professionals towards the HIS, only "gender" $(p=0.009)$ and "occupation categories" ( $p=0.007)$ seem to influence this attitude and specifically the dimension "Providing quality care to the patient", whereas "previous experience in use of computers at work" affects the dimension "Reduction in jobs" ( $p=$ $0.009)$. Conclusions: The statistical analysis of the data showed that the employees of the General Oncology Hospital under study have a positive attitude towards the use of the integrated Hospital Informatics Systems (HISs). Males tend to have the most positive attitude while employees who already make use of personal computers in their work, tend to disagree with the view that HIS will lead to a job reduction.
\end{abstract}


Keywords

Hospital Information Systems, Attitudes of Health Professionals, ICT

\section{Introduction}

Modern Hospital Information Systems (HIS) in the health sector, make a major contribution to the effective recording and processing of a large volume of data on both medical and nursing functions as well as on the administrative and financial functions of the health units. This results in the effective improvement of the provided health services, a more efficient cost monitoring and the daily convenience of health professionals and citizens-users alike (Dixon \& Stewart, 2000; Aceto, Persico, \& Pescape, 2018). Health sector in Greece, is perhaps one of the few sectors where information and communication technologies have a disproportional development. Unfortunately, a large part of the information is still circulated in the traditional (manuscript) fashion, despite the vast experience and successful integration of IT in other fields (Vagelatos \& Sarivougioukas, 2001, Kalafati, 2003).

According to research, the situation in recent years seems to be changing. Health professionals and patients are more trained and at the same time more demanding in terms of the use of Information and Communication Technologies (ICT). On the one hand, the need for better cost management in hospitals and on the other hand, the demand for better health services require the development and integration of Hospital Information Systems.

Additionally, the huge demands to cope with the increasing wealth of health information, in parallel with the urge to increase the efficiency and productivity of health professionals make the need for integration of automation in the health sector an imperative (Aceto, Persico, \& Pescape, 2018).

Yet, prior to the implementation of any innovative project, such as a HIS, the positive attitude of the employees who will be the main users must be ensured and also the factors that affect it should be specified. That is why the attitude of health professionals towards the application and use of Hospital Information Systems as well as the elements that influence them to be positive or negative towards computerization is one of the principal issues in information systems research in general but also one of the key issues for further analysis in the present study.

More specifically, this study will seek to research the attitudes of health professionals towards the integration of Hospital Information Systems, to identify the sociodemographic factors that shape it and also to fill the gap in the literature since, most of the relative research has been carried out only for the nursing staff and not for the other health occupational categories.

\section{Literature Review}

Based on the literature review it was discerned that most of the studies carried 
out up to now, mainly concern the attitude of nurses towards HIS, since they constitute the largest health professional group of the health units (Kalafati, 2003). However, there were a few studies addressed to administrative staff and physicians as well. Yet, the findings of all those studies were not consisted.

More specifically, many of these studies (Banihani et al., 2019; Salameh et al., 2019; Kivuti \& Chepchirchir, 2011; Brumini et al., 2005; Alquraini et al., 2007; Teo, 2008; Kalafati, 2003), showed that health professionals have a positive attitude towards computerization, except for the work of Sultana (1990) who studied only the nursing staff and showed that they have a negative attitude towards computers.

Reports from other studies showed that gender affects the attitude of health professionals, such as the work of Vozikis et al. (2010) and the one of Kalafati (2003) where men seem to have a more positive attitude towards the use of computers than women. However, the research of Alquraini et al., (2007) showed that women have more positive attitude toward computerization than men, and other studies (Kipturgo et al., 2014; Teo, 2008; Meelissen \& Drent, 2008) showed that gender has no effect on nurses' attitudes toward computerization.

Literature review (Kipturgo et al., 2014; Ward et al., 2008; Alquraini et al.; 2007, Kalafati, 2003; Stronge \& Brodt, 1985) has also showed that education is a factor that forms a more positive attitude towards HIS, and specifically for employees with a higher education who appear to have a more positive attitude towards computerization. However, the research of Tsoromokos et al. (2015) showed no relation between the level of education and health professionals' attitudes.

Furthermore, other studies (Kalafati, 2003; Tsoromokos et al., 2015) reported that educational category is a factor that affects the attitude towards computerization. According to these studies doctors and nurses, seem to be more familiar with the use of new technologies and to gradually move from their previous negative attitudes. However, a survey on health professionals conducted in 2004 in Norway had opposite results, since a more positive attitude was observed for administrative staff who tend to use information systems more often than doctors and nurses (Laerum et al., 2004).

Studies also showed that age is a significant factor as regards the attitude of health professionals towards information technology. The work of Brumini et al. (2005), a study conducted in Kenya by Kipturgo et al. (2014) and also the work of Vozikis et al. (2010) showed that younger nurses tend to have a more positive attitude towards hospital information systems. However, these findings are not supported by the work of Getty et al. (1999), the work of Scarpa et al. (1992), or the work of Chan et al. (2004) who did not show that age has any influence on the attitudes of health professionals towards the implementation of HIS.

Other studies such the one of Sultana's (1990), and the study of Kipturgo et al. (2014), argued that overall-general previous job experience did not affect the respondents' attitudes towards computerization. Yet the research of Kalafati, 
2003, proved that professional experience significantly affects their attitudes towards computer integration and less experienced employees tend to have a more positive attitude.

Finally literature (Ammenwerth et al., 2003; Moody et al., 2004; Vozikis et al., 2010; Wilson, 1991; Large, 1994), supports that employees who use computers at work developed more positive attitudes towards new technologies and were not of the opinion that computers usage and integration will lead to a job reduction within a health organization, but will instead improve the quality of the services provided.

\section{Material and Method}

In order to analyze the attitude of the Health Professionals of a General Oncology Hospital of Attica towards the Integrated Hospital Information Systems, as well as the influence of socio-demographic factors in its formation, a quantitative sample survey was conducted with the implementation of the NATC (Nurses Attitudes toward Computerization) questionnaire (Stronge \& Brodt, 1985). This tool is used internationally to measure the attitude of Nursing Staff in the use of Information Systems in the Health Sector and has been employed by many researchers not exclusively for nursing staff, but also for other categories of hospital staff such as medical, administrative, technical etc. The questionnaire has been adapted to the Greek language and properly validated by Kalafati (2003). It comprises 20 different questions which constitute five distinct categories-dimensions that record the attitude of employees towards the use of HIS. These categories are the following: a) Providing quality care to patients due to the use of HIS in the hospital, which includes questions 3, 8, 10, 15, 17 and 19, b) benefits to the hospital from the use of HIS that consists of questions 1, 2, 4 and $16, \mathrm{c}$ ) reduction of jobs due to the use of HISs in the hospital, which comprises question 18, d) increasing efficiency and staff capabilities that includes questions $5,7,11,12,13$ and 14 and e) increasing the legal responsibility of staff from the use of HISs, which consists of questions 6, 9 and 20. The answers to these 20 questions are recorded on a five-point Likert scale, coded according to the instructions of its creators as follows: Strongly agree $=1$, Agree $=2$, I am uncertain $=3$, Disagree $=4$ and Strongly disagree $=5$, while the questions 3,8 , 13,14 , and 19 of the questionnaire were reversed in terms of their coding because they had the opposite conceptual direction.

In addition, the social and demographic characteristics of the participants were recorded, and more specifically the age, gender, level of education, occupational category, years of service, general experience with computers, use of computers in their job, etc. in order to research their influence on their attitude towards the HIS.

The population of the study includes all the Medical, Nursing and Administrative staff of the certain General Oncology Hospital with no exclusion criteria. The study design was cross-sectional and the sampling scheme was the stratified sampling. The stratification process was based on the specialty of the partici- 
pants and as such, the population was divided into mutually exclusive sub-groups (doctors, nurses, and administrative staff). Simple random sampling with a random-sample generating procedure was applied in each stratum in order to select sample from each subgroup. The objective of the selected method was to improve the precision of the sample by reducing the sampling error.

With this procedure a sample of 180 healthcare professionals was drawn. A written consent form was signed by every participant and all participants were informed that the collected information is confidential and will be used for research purposes only. A very high percentage of the respondents completed and returned the questionnaires (150 valid questionnaires were returned which corresponds to a response rate of $83.33 \%$ ).

The survey was conducted between October and December 2019. The average completion time took 15 to 20 minutes. Throughout the data collection process, the revised Helsinki Declaration (Carlson, Boyd, \& Webb, 2004) as well as the principles of research ethics were observed. The participants were fully informed about the purpose and special research objectives as well as that their personal data will remain confidential. The data collection started upon approval of the scientific council-bioethics committee.

The current research was carried out within the framework of the Postgraduate Program "Health and Social Care Management" of the University of West Atticaand its main objective is to research the attitudes of health professionals of a General Oncology Hospital of Attica towards the Integrated Hospital Information Systems as well as the socio-demographic factors that possibly affect its degree and emergence.

\section{Statistical Analysis}

Data analysis was carried out with the use of SPSS 25. The five dimensions of NATC (Nurses Attitudes towards Computerization) were calculated as the mean values of the variables/questions that comprise them. One sample $t$-test and the non-parametric Wilcoxon signed rank test was used to determine statistically significant differences between the sample and the theoretically neutral mean or median (neutral mean and median $=3.0$ ). Independent samples $t$-test and Mann-Whitney $U$ test were used to determine possible statistically significant differences of the NATC dimensions between two independent groups. Also, ANOVA and the non-parametric Kruskal-Wallis- $\mathrm{H}$ test were used to determine statistically significant differences of the NATC dimensions between more than two groups (with post-hoc analysis based on non-parametric Mann-Whitney U test with Bonferroni correction). Finally, Pearson's $r$ and Spearman's Rho correlation coefficients were used to test for linear correlation between "years of experience" and "age" with the NATC dimensions. Non-parametric tests were only implemented in those occasions where either the variables were ordinal or the distribution of the variable had high skewness and at the same time there were a lot of outliers since the $t$-test and ANOVA are very robust in deviations from 
normality. The level of statistical significance was set to $\alpha=0.05$.

Regarding the sampling frame, $26.7 \%$ are males and $73.3 \%$ are females. As it was expected most of the health professionals that participated in the research (40.0\%) are nurses, $31.3 \%$ are administrative staff and $28.7 \%$ are doctors. It is worth noting that $33.3 \%$ of the participants are university graduates, $23.33 \%$ of those have graduated from a technological educational institute and a large percentage of $21.33 \%$ hold a postgraduate title (an M.Sc. and/or a Ph.D.). Moreover $89.33 \%$ of respondents have answered that they are familiar with and experienced in computers in general, whereas only $10.9 \%$ has answered that they have no experience. Also $88.0 \%$ of the participants replied that they use computers in their job. The average age of the participants is $43.8 \pm 9.57$, with median age of 43.5. Additionally, their average professional experience is $16.98 \pm 10.67$, with a median value of 16.0 years.

Employing the $t$-test as well as the non-parametric one sample Wilcoxon signed rank test has shown that the attitude of the personnel of the General Oncology Hospital under study towards the integrated HISs is positive (Table 1). The above is justified since the 5 categories that describe this attitude are statistically greater that the neutral average or median value of $3.0(p<0.05)$ and as such according to the creators of the questionnaire the presence of high values in these categories justifies a positive attitude towards HISs.

In order to check for the presence of statistically significant differences in the mean values of the five categories of the NATC questionnaire, between males and females we employed the independent samples $t$-test and the Mann-Whitney $\mathrm{U}$. The results have shown that there are statistically significant differences $(p<$ 0.05 ) for the $1^{\text {st }}$ subscale only (Table 2 ), where males appear to hold a more positive attitude $($ mean $=3.67)$ compared to females $($ mean $=3.43)$ in regards of the contribution of HIS to the provision of a quality health care to patients.

The next step involves checking for statistically significant differences in the mean or median values of the five dimensions of NATC between the occupation

Table 1. Results of one sample T-test and Wilcoxon signed rank for the five NATC subscales.

\begin{tabular}{|c|c|c|c|c|}
\hline NATC subscale & $\mathbf{N}$ & Mean & Median & Test \\
\hline Providing quality care & 150 & 3.49 & 3.50 & $\begin{array}{c}t=11.96 \\
p<0.001^{*}\end{array}$ \\
\hline Benefits of hospital & 150 & 3.67 & 3.75 & $\begin{array}{c}t=10.53 \\
p<0.001^{\star}\end{array}$ \\
\hline Increasing efficiency and staff capabilities & 150 & 4.08 & 4.17 & $\begin{array}{c}t=19.91 \\
p<0.001^{\star}\end{array}$ \\
\hline Increasing the legal responsibility & 150 & 3.70 & 4.00 & $\begin{array}{l}\mathrm{Z}=8576.5 \\
P<0.001^{\star}\end{array}$ \\
\hline Reduction of jobs & 150 & 3.49 & 4.00 & $\begin{array}{l}\mathrm{Z}=5381.5 \\
p<0.001^{\star}\end{array}$ \\
\hline
\end{tabular}

*Statistically significant at the level of significance $(p<0.05)$. 
Table 2. Independent samples $t$-test and Mann-Whitney U results for gender.

\begin{tabular}{cccccc}
\hline NATC subscale & Gender & N & Mean & Median & Test \\
\hline Providing quality care & M & 40 & 3.67 & 3.67 & $t=2.63$ \\
& F & 110 & 3.43 & 3.50 & $p=0.009^{*}$ \\
Benefits of hospital & M & 40 & 3.63 & 3.75 & $t=-0.351$ \\
Increasing efficiency & F & 110 & 3.68 & 3.75 & $p=0.726$ \\
and staff capabilities & M & 40 & 4.17 & 4.33 & $t=1.05$ \\
Increasing the legal & F & 110 & 4.04 & 4.08 & $p=0.295$ \\
responsibility & M & 40 & 3.78 & 4.00 & $t=0.743$ \\
Reduction of jobs & F & 110 & 3.67 & 3.67 & $p=0.459$ \\
& M & 40 & 3.65 & 4.00 & $\mathrm{U}=1.89$ \\
& F & 110 & 3.44 & 4.00 & $p=0.155$ \\
\hline
\end{tabular}

*Statistically significant at the level of significance $(p<0.05)$.

categories (nurses, doctors and administrative staff). Tests were carried out using the ANOVA as well as the non-parametric Kruskal-Walis $\mathrm{H}$ test. Both tests have shown a statistically significant difference for the $1^{\text {st }}$ dimension only, which justifies that the occupational categories have an effect on the attitude formation of the employees as regards the contribution of HIS to the provision of a quality health care to patients. Post-hoc analysis based on the non-parametric Mann-Whitney $U$ with Bonferroni correction has shown a statistically significant difference only for the pair (doctor-nurse $(p<0.05)$ ) with doctors having a more positive attitude (mean $=3.67)$ compared to nurses $($ mean $=3.33)($ Table 3$)$. From the above table we can discern that doctors have the highest mean and median value for the specific subscale compared to the other occupational categories.

Statistical analysis with ANOVA as well as with Kruskal-Walis $\mathrm{H}$ test was performed so as to check for statistical significant differences in the mean or median values of the NATC dimensions among the education levels of employees (secondary education, higher education and M.Sc./Ph.D holders). The analysis has shown a statistically significant difference for the fifth dimension only, a result which shows that the education level has an effect on the attitude formation of the employees regarding the opinion that HIS integration will lead to job reduction. Post-hoc analysis based on the non-parametric Mann-Whitney $\mathrm{U}$ test with Bonferroni correction has shown a statistically significant difference only for the pair secondary education-higher education $(p<0.05)$ with higher education employees disagreeing with the opinion that the HIS integration will lead to a job reduction (mean rank secondary education $=46.67$, mean-rank higher-education $_{\text {in }}=$ 64.48) (Table 4).

In order to test for correlation between factors "age", "job experience" and the subscales of NATC we used Pearson's $r$ test as well as the non-parametric Spearman's Rho test. The results have shown that there is no statistically significant 
Table 3. Results of one-way ANOVA and Kruskal-Walis $\mathrm{H}$ tests for occupation category with Bonferroni correction.

\begin{tabular}{|c|c|c|c|c|c|}
\hline NATC subscale & Occupation Category & $\mathbf{N}$ & Mean & Median & Test \\
\hline \multirow{3}{*}{ Providing quality care } & Nurse & 60 & 3.36 & 3.33 & \multirow{3}{*}{$\begin{array}{c}\mathrm{F}=5.08 \\
p=0.007^{\star}\end{array}$} \\
\hline & Doctor & 47 & 3.66 & 3.67 & \\
\hline & Administrative & 43 & 3.50 & 3.50 & \\
\hline \multirow{3}{*}{ Benefits of hospital } & Nurse & 60 & 3.60 & 3.75 & \multirow{3}{*}{$\begin{array}{l}\mathrm{F}=2.87 \\
p=0.06\end{array}$} \\
\hline & Doctor & 47 & 3.54 & 3.75 & \\
\hline & Administrative & 43 & 3.90 & 4.00 & \\
\hline \multirow{3}{*}{$\begin{array}{l}\text { Increasing efficiency } \\
\text { and staff capabilities }\end{array}$} & Nurse & 60 & 3.99 & 4.00 & \multirow{3}{*}{$\begin{array}{l}\mathrm{F}=2.67 \\
p=0.07\end{array}$} \\
\hline & Doctor & 47 & 4.01 & 4.17 & \\
\hline & Administrative & 43 & 4.27 & 4.33 & \\
\hline \multirow{3}{*}{$\begin{array}{l}\text { Increasing the } \\
\text { legal responsibility }\end{array}$} & Nurse & 60 & 3.67 & 3.667 & \multirow{3}{*}{$\begin{array}{l}\mathrm{F}=0.05 \\
p=0.95\end{array}$} \\
\hline & Doctor & 47 & 3.70 & 4.00 & \\
\hline & Administrative & 43 & 3.72 & 4.00 & \\
\hline \multirow{3}{*}{ Reduction of jobs } & Nurse & 60 & 3.43 & 4.00 & \multirow{3}{*}{$\begin{aligned} \mathrm{H} & =4.97 \\
p & =0.08\end{aligned}$} \\
\hline & Doctor & 47 & 3.77 & 4.00 & \\
\hline & Administrative & 43 & 3.28 & 4.00 & \\
\hline
\end{tabular}

${ }^{\star}$ Statistically significant at the level of significance $(p<0.05)$.

Table 4. Results of one-way ANOVA and Kruskal-Walis $\mathrm{H}$ tests for education level with Bonferroni correction.

\begin{tabular}{|c|c|c|c|c|c|}
\hline NATC subscale & Education Level & $\mathbf{N}$ & Mean & Median & Test \\
\hline \multirow{3}{*}{ Providing quality care } & Secondary & 33 & 3.35 & 3.33 & \multirow{3}{*}{$\begin{array}{l}\mathrm{F}=2.326 \\
P=0.101\end{array}$} \\
\hline & Higher & 85 & 3.49 & 3.67 & \\
\hline & M.Sc./Ph.D. & 32 & 3.62 & 3.67 & \\
\hline \multirow{3}{*}{ Benefits of hospital } & Secondary & 33 & 3.57 & 3.75 & \multirow{3}{*}{$\begin{array}{l}\mathrm{F}=0.609 \\
p=0.545\end{array}$} \\
\hline & Higher & 85 & 3.66 & 3.75 & \\
\hline & M.Sc./Ph.D. & 32 & 3.78 & 4.00 & \\
\hline \multirow{3}{*}{$\begin{array}{l}\text { Increasing efficiency } \\
\text { and staff capabilities }\end{array}$} & Secondary & 33 & 3.93 & 4.00 & \multirow{3}{*}{$\begin{array}{c}\mathrm{F}=1.566 \\
p=0.07\end{array}$} \\
\hline & Higher & 85 & 4.08 & 4.17 & \\
\hline & M.Sc./Ph.D. & 32 & 4.22 & 4.37 & \\
\hline \multirow{3}{*}{$\begin{array}{l}\text { Increasing the legal } \\
\text { responsibility }\end{array}$} & Secondary & 33 & 3.39 & 3.667 & \multirow{3}{*}{$\begin{aligned} \mathrm{H} & =4.778 \\
p & =0.92\end{aligned}$} \\
\hline & Higher & 85 & 3.76 & 4.00 & \\
\hline & M.Sc./Ph.D. & 32 & 3.83 & 4.00 & \\
\hline \multirow{3}{*}{ Reduction of jobs } & Secondary & 33 & 2.97 & 3.00 & \multirow{3}{*}{$\begin{array}{l}\mathrm{H}=7.825 \\
p=0.006^{*}\end{array}$} \\
\hline & Higher & 85 & 3.67 & 4.00 & \\
\hline & M.Sc./Ph.D. & 32 & 3.56 & 4.00 & \\
\hline
\end{tabular}

${ }^{\star}$ Statistically significant at the level of significance $(p<0.05)$. 
correlation for any subscale and as such one can infer that neither age nor job experience have an effect on attitude formation for health professional towards HIS (Table 5).

Checking for the presence of statistically significant differences between the mean values of five NATC subscales between employees who were using computers in general and those who did not, no statistically significant differences were detected for any subscale $(p>0.05)$. This implies that the general use and familiarity with computers do not have any effect on the employees' attitude towards HIS (Table 6).

As opposed to the previous results, checking for statistically significant differences between the mean values of the five subscales of NATC among those employees who were using computers in their jobs and those who were not, the Mann-Whitney U test has shown statistically significant differences only for the subscale that evaluates the employee's attitude towards job reduction. More

Table 5. Pearson's $r$ and spearman's rho results.

\begin{tabular}{ccc}
\hline NATC subscale & $\begin{array}{c}\text { Correlation } \\
(\text { Age })\end{array}$ & $\begin{array}{c}\text { Correlation } \\
\text { (Total professional experience) }\end{array}$ \\
\hline Providing quality care & Pearson $=-0.036$ & Pearson $=0.062$ \\
& $p=0.664$ & $p=0.448$ \\
Benefits of hospital & Pearson $=0.008$ & Pearson $=0.044$ \\
Increasing efficiency & $p=0.921$ & $p=0.597$ \\
and staff capabilities & Pearson $=0.029$ & Pearson $=0.007$ \\
& $p=0.729$ & $p=0.934$ \\
Increasing the legal responsibility & Pearson $=-0.060$ & Pearson $=0.005$ \\
& $p=0.463$ & $p=0.950$ \\
Reduction of jobs & Spearman $=0.052$ & Spearman $=0.047$ \\
& $p=0.528$ & $p=0.571$
\end{tabular}

Table 6. Independent samples $t$-test and Mann-Whitney $U$ results for general use of computers.

\begin{tabular}{cccccc}
\hline NATC subscale & General use of computers & N & Mean & Median & Test \\
\hline \multirow{2}{*}{ Providing quality care } & $\mathrm{N}$ & 16 & 3.3854 & 3.67 & $\mathrm{U}=1010.5$ \\
& $\Upsilon$ & 134 & 3.5037 & 3.50 & $p=0.706$ \\
Benefits of hospital & $\mathrm{N}$ & 16 & 3.6719 & 3.75 & $t=0.019$. \\
& $\Upsilon$ & 134 & 3.6679 & 3.75 & $p=0.985$ \\
$\begin{array}{c}\text { Increasing efficiency } \\
\text { and staff capabilities }\end{array}$ & $\mathrm{N}$ & 16 & 3.9479 & 3.92 & $t=1.177$ \\
& $\Upsilon$ & 134 & 4.0920 & 4.25 & $p=0.250$ \\
Increasing the legal & $\mathrm{N}$ & 16 & 3.4375 & 3.67 & $t=1.389$ \\
responsibility & $\Upsilon$ & 134 & 3.7264 & 4.00 & $p=0.167$ \\
Reduction of jobs & $\mathrm{N}$ & 16 & 3.06 & 3.50 & $\mathrm{U}=824.0$ \\
& $\Upsilon$ & 134 & 3.54 & 4.00 & $p=0.104$ \\
\hline
\end{tabular}


specifically persons experienced in working with computers disagree with the opinion that their usage will lead to a job reduction (Table 7).

\section{Discussion}

The main purpose of the current study is to research the attitude of health professionals towards hospital information systems as well as the socio-demographic factors that influence this attitude. The NATC (Nurses Attitudes toward Computerization) questionnaire of Stronge \& Brodt (1985) was given to participants, which it consists of 20 different questions which constitute five categories/subscales that reflect employees' attitudes toward the use of computers in hospitals. These categories are as follows: 1) Providing quality care to patients from the use of HIS's; 2) Hospital benefits from the use of HIS; 3) Job reduction due to the use of HIS; 4) Increasing efficiency and staff capabilities and 5) Increasing the legal responsibility of staff from the use of HIS.

The main conclusions reached can be summarized as follows:

The employees of the General Oncology Hospital under study, have, in general, a positive attitude towards the Integrated Hospital Information Systems since all the subscales that determine it were statistically significantly higher than the theoretically neutral average or median value. This result is in line with other studies (Banihani et al., 2019; Salameh et al., 2019; Kivuti \& Chepchirchir, 2011; Brumini et al., 2005; Alquraini et al., 2007; Teo, 2008; Kalafati, 2003) and in contrast only to that of Sultana (1990) who studied however only the nursing staff and showed, as earlier mentioned, that they have a negative attitude towards computers. Yet, it is noted that the attitude of professionals towards the implementation of HISs has improved over time (Kipturgo et al., 2014).

The effect of gender was statistically significant only in terms of the "quality of care provided to patients" through the use of HIS. The analysis revealed that

Table 7. Independent samples $t$-test and Mann-Whitney u results for use of computers at work.

\begin{tabular}{cccccc}
\hline NATC subscale & Use of computers in work & N & Mean & Median & Test \\
\hline Providing quality care & $\mathrm{N}$ & 16 & 3.315 & 3.33 & $t=1.593$ \\
& $\Upsilon$ & 134 & 3.52 & 3.50 & $p=0.113$ \\
Benefits of hospital & $\mathrm{N}$ & 16 & 3.51 & 3.50 & $t=0.879$ \\
& $\Upsilon$ & 134 & 3.69 & 3.75 & $p=0.371$ \\
$\begin{array}{c}\text { Increasing efficiency } \\
\text { and staff capabilities }\end{array}$ & $\mathrm{N}$ & 16 & 3.84 & 3.83 & $t=1.607$ \\
& $\Upsilon$ & 134 & 4.12 & 4.25 & $p=0.110$ \\
Increasing the legal & $\mathrm{N}$ & 16 & 3.44 & 3.50 & $\mathrm{U}=886.0$ \\
responsibility & $\Upsilon$ & 134 & 3.73 & 4.00 & $p=0.077$ \\
Reduction of jobs & $\mathrm{N}$ & 16 & 2.94 & 3.00 & $\mathrm{U}=769.0$ \\
& $\Upsilon$ & 134 & 3.57 & 4.00 & $p=0.009^{*}$ \\
\hline
\end{tabular}

*Statistically significant at the level of significance $(p<0.05)$. 
men hold a more positive attitude towards the use of computers compared to women. This may be due to the fact that men tend to have a higher familiarization with ICT and have developed as such a more positive attitude than women towards the contribution of information systems to providing quality care to patients. This result is in line with the work of Vozikis et al. (2010) in which men showed higher values than women in three of the five factors of NATC, as well as the work of Kalafati (2003) where men seem to have a more positive attitude towards the use of computers than women.

Statistical analysis also showed that the occupational category factor has a statistically significant effect on the formation of employees' attitudes regarding the contribution of HISs to the "quality of care provided to patients". Significant differences are observed between nurses and doctors with the latter having a more positive attitude, considering that the use of HIS will highly contribute to the provision of quality health care, while increasing staff efficiency. The above results are supported by the study elaborated by Kalafati (2003) and the work of Tsoromokos et al. (2015) specifically in terms of the attitude of doctors and nurses, who seem to gradually change their previous negative attitudes. A survey of health professionals conducted in 2004 in Norway had opposite results, since a more positive attitude was observed for administrative staff who tend to use information systems more often than doctors and nurses (Laerum et al., 2004).

Concerning the education level of the employees, statistical analysis has shown that it has a significant effect on the formation of their attitude towards HIS only regarding the dimension "integration will lead to job reduction". Significant differences are only observed between secondary education employees and higher education employees, with the latter having a more positive attitude towards HIS integration and were not of the opinion that computers usage and HIS integration will lead to a job reduction. This result is in line with other studies (Ward et al., 2008; Alquraini et al.; 2007, Kipturgo et al., 2014, Kalafati, 2003) who showed that education is a factor that shapes a more positive attitude towards HIS and specifically for employees with a higher education who have a more positive attitude towards computerization. Yet is in contrast to the research of Tsoromokos et al. (2015) who showed no relation between the level of education and health professional attitudes.

Statistical analysis has also revealed that the age effect on the five dimensions of NATC was not statistically significant. This means that age does not affect the formation of the attitude of health professionals towards HISs. This finding is supported by the work of Getty et al. (1999) who found that positive and negative scores were evenly distributed across the age groups. Scarpa et al. (1992) too, found no such correlation between age and attitudes. Similarly, in Chan et al. (2004) study it was found that age has not any influence on the attitudes of health professionals towards the implementation of HIS. The above finding however, is in contrast with other research findings, such as the work of Brumini et al. (2005), which showed that younger nurses tend to have a more positive attitude towards hospital information systems, or the work of Vozikis et al. (2010) 
which showed that younger employees, probably due to their higher degree of familiarization with new technologies, have a more positive attitude towards HISs as well as a study conducted in Kenya by Kipturgo et al. (2014), according to which a significant correlation was observed between the age and the attitude of the nursing staff towards the use of computers.

The same applies to the five dimensions that compose the attitude of health professionals towards HISs in relation to their total years of service since there was no statistically significant correlation. This finding means that the overall length of service of employees does not affect the formation of the attitude of health professionals towards HISs. This result is also supported by the research of Kipturgo et al. (2014) and in Sultana's study (1990), where it was found that the job experience in the nursing profession did not significantly affect the respondents' attitudes towards computer integration. However, this finding is not verified by the results of other research studies such as the work of Kalafati (2003) which proved that employees with less professional experience were more positive towards computerization than the more experienced employees who were neutral. This may be due to the fact that senior employees may hold executive or senior positions and tend to allocate work that requires the use of technology to younger employees and therefore feel that technology plays only a supportive role in the overall work procedure.

The analysis also showed that although general use, familiarity and experience in computers does not seem to affect the attitude of health professionals, the experience in the use of computers acquired in the workplace, seems to positively affect the attitude of participants concerning the use of HISs. More specifically, according to the results of this survey, employees with experience in computers in their workplace, disagree with the view that HISs can lead to a job reduction and are of the opinion that the institution will benefit from the introduction and use of ICT. The same holds for the findings of other surveys (Ammenwerth et al., 2003; Moody et al., 2004; Vozikis et al., 2010; Wilson, 1991; Large, 1994), which showed that employees who use computers at work developed more positive attitudes towards new technologies and were not of the opinion that computers usage and integration will lead to a job reduction within a health organization.

\section{Conclusion}

The findings of the present study made it possible to research and understand the attitude of the health professionals of the General Oncology Hospital under study towards HISs. Results have shown that the attitude of health professionals is beginning to change, and HISs are nowadays considered as an integrated tool that facilitates labor and benefits the institution by improving the quality of its services.

At the same time, there were limitations and questions, which pave the way for future proposals and extensions. A key limiting research factor is that the sample is solely based on employees from a single health unit. Thus, the results 
can only be generalized for employees of the specific unit and not for all the employees in similar health units (Goula et al., 2018), and for that reason, a large-scale research would ensure greater reliability and generalization of results at a methodological level. Furthermore, a similar research in a general hospital and the comparison of the results with the findings of the current study may reveal additional useful information.

It is also worth noting the refusal of several employees, mainly administrative staff and doctors to participate in the current research due to their workload. In contrast, the nursing staff was more willing to participate and as such they constitute the largest part of the sample. It is also highlighted that differences in the employees background between occupational categories should be taken into account and for that reason absolute conclusions drawn from the survey results should be treated with caution.

To conclude, it is important to mention that prior to the implementation of any innovative project, such as an HIS, the positive attitude and consent of the employees who will use it must be ensured. Thus, the practical implication of the current study is that its findings will pave the way towards the acceptance and the integration of a user friendly and easy to use hospital information system that would meet the expectations of the employees.

\section{Conflicts of Interest}

The authors declare no conflicts of interest regarding the publication of this paper.

\section{References}

Aceto, G., Persico, V., \& Pescape, A. (2018). The Role of Information and Communication Technologies in Healthcare: Taxonomies, Perspectives, and Challenges. Journal of Network and Computer Applications, 107, 125-154.

https://doi.org/10.1016/j.jnca.2018.02.008

Alquraini, H., Alhashem, A. M., Shah, M. A., \& Chowdhury, R. I. (2007). Factors Influencing Nurses' Attitudes towards the Use of Computerized Health Information Systems in Kuwaiti Hospitals. Journal of Advanced Nursing, 57, 375-381.

https://doi.org/10.1111/j.1365-2648.2007.04113.x

Ammenwerth, E., Mansmann, U., Iller, C., \& Eichstadter, R. (2003). Factors Affecting and Affected by User Acceptance of Computer-Based Nursing Documentation: Results of a Two-Year Study. Journal of the American Medical Informatics Association, 10, 69-84. https://doi.org/10.1197/jamia.M1118

Banihani, S., Al Qadire, M., \& E'leimat, D. A. (2019). Attitudes of Jordanian Oncology Nurses toward Computerization. Journal of Cancer Education. https://doi.org/10.1007/s13187-019-01636-w

Brumini, G., Kovic, I., Zombori, D., Lulic, I., \& Petrovecki, M. (2005). Nurses’ Attitudes towards Computers: Cross Sectional Questionnaire Study. Croatian Medical Journal, 46, 101-104.

Carlson, R. V., Boyd, M. K., \& Webb, J. D. (2004). The Revision of the Declaration of Helsinki: Past, Present and Future. British Journal of Clinical Pharmacology, 57, 695-713. https://doi.org/10.1111/j.1365-2125.2004.02103.x 
Chan, T., de Lusignan, S., \& Brew, S. (2004). Overcoming the Barriers to Using Information Systems. Nursing Times, 100, 44-46.

Dixon, D. R., \& Stewart, M. (2000). Exploring Information Technology Adoption by Family Physicians: Survey Instrument Valuation. Proceedings of the AMIA Symposium, Los Angeles, CA, 185-189.

Getty, M., Ryan, A. A., \& Ekins, M. L. (1999). A Comparative Study of the Attitudes of Users and Non-Users towards Computerized Care Planning. Journal of Clinical Nursing, 8 , 431-439. https://doi.org/10.1046/j.1365-2702.1999.00273.x

Goula, A., Katelouzou, D., Pierrakos, G., Latsou, D., Dimakou, S., Stamouli, A., \& Natsis, Ch. (2018). Analysis of the Relationship between Transformational Leadership and Learning Organizational in Health Care Services. In A. Kavoura, E. Kefallonitis, \& A. Giovanis (Eds.), Springer Proceedings in Business and Economics Book Series (SPBE) (pp. 155-163). Cham: Springer. https://doi.org/10.1007/978-3-030-12453-3 18

Kalafati, M. (2003). Attitude of Health Professionals towards the Implementation of Hospital Information Systems. Ph.D. Thesis, Athens: National University of Athens.

Kipturgo, M. K., Kivuti-Bitok, L. W., Karani, A. K., \& Muiva, M. M. (2014). Attitudes of Nursing Staff towards Computerization: A Case of Two Hospitals in Nairobi, Kenya. BMC Medical Informatics and Decision Making, 14, Article No. 35.

https://doi.org/10.1186/1472-6947-14-35

Kivuti, L., \& Chepchirchir, A. (2011). Computerization Readiness. Online Journal of Nursing Informatics, 15, 178. http://ojni.org/issues/? $p=178$

Laerum, H., Karlsen, T. H., \& Faxvaag, A. (2004). Use of and Attitudes to a Hospital Information System by Medical Secretaries, Nurses and Physicians Deprived of the Paperbased Medical Record: A Case Report. BMC Medical Informatics and Decision Making, 4, Article No. 18. https://doi.org/10.1186/1472-6947-4-18

Large, W. P. (1994). Nurses' Attitudes towards Computerization in Intensive Care. British Journal of Nursing, 3, 558-564. https://doi.org/10.12968/bjon.1994.3.11.558

Meelissen, M. R. M., \& Drent, M. (2008). Gender Differences in Computer Attitudes: Does the School Matter? Computers in Human Behavior, 24, 969-985. https://doi.org/10.1016/j.chb.2007.03.001

Moody, L. E., Slocumb, E., Berg, B., \& Jackson, D. (2004). Electronic Records Documentation in Nursing: Nurses' Perceptions, Attitudes, and Preferences. CIN: Computers, Informatics, Nursing, 22, 337-344. https://doi.org/10.1097/00024665-200411000-00009

Salameh, B., Eddy, L. L., Batran, A., Hijaz, A., \& Jaser, S. (2019). Nurses' Attitudes toward the Use of an Electronic Health Information System in a Developing Country. SAGE Open Nursing, 5, 1-8. https://doi.org/10.1177/2377960819843711

Scarpa, R., Smeltzer, S. C., \& Jasion, B. (1992). Attitudes of Nurses toward Computerization: A Replication. Computers in Nursing, 10, 72-80.

Stronge, J. H., \& Brodt, A. (1985). Assessment of Nurses' Attitudes toward Computerization. Computers in Nursing, 3, 154-158.

Sultana, N. (1990). Nurses' Attitudes towards Computerization in Clinical Practice. Journal of Advanced Nursing, 15, 696-702.

https://doi.org/10.1111/j.1365-2648.1990.tb01893.x

Teo, T. (2008). Assessing the Computer Attitudes of Students: An Asian Perspective. Computers in Human Behavior, 24, 1634-1642.

https://doi.org/10.1016/j.chb.2007.06.004

Tsoromokos, D., Harami, E., Dermatis, Z. A., \& Lazakidou, A. (2015). Knowledge and Attitudes from Healthcare Professionals toward to the Computers. International Jour- 
nal of Health Research and Innovation, 3, 29-47.

Vagelatos, A., \& Sarivougioukas, J. (2001). Hospital Information System: Necessary Infrastructure in Today's Hospital. (In Greek)

http://www.iatrolexi.gr/vagelat/Iatriki 2001.pdf

Vozikis, A., Ypofanti, M., \& Papadopoulos, I. (2010). Attitudes towards the Use of Information and Communication Technologies (ICT) at Work: Findings from the Health Care Sector in Greece. SPOUDAI Journal of Economics and Business, 60, 82-96.

https://www.semanticscholar.org/paper/Attitudes-towards-the-use-of-information-and -(ICT)-Vozikis-Ypofanti/24320733bd27826098d5bd996ac23237d4009051\#citing-paper $\underline{\mathrm{s}}$

Ward, R., Stevens, C., Brentnall, P., \& Briddon, J. (2008). The Attitudes of Health Care Staff to Information Technology: A Comprehensive Review of the Research Literature. Health Information and Libraries Journal, 25, 81-97. https://doi.org/10.1111/j.1471-1842.2008.00777.x

Wilson, B. A. (1991). Computer Anxiety in Nursing Students. Journal of Nursing Education, 30, 52-56. 